\title{
DE LEOVIGILDO PERSEGUIDOR Y MASONA MÁRTIR
}

From the behaviour and the characterization of the protagonists, the topoi, the literary sources and the language one infers that the conflict depicted in the Vitas Sanctorum Patrum Emeretensium between the Arian king Leovigild and the Catholic

bishop Masona is written according to the model of the passions of martyrs.

El enfrentamiento entre el obispo católico de Mérida Masona y el rey arriano Leovigildo constituye el argumento básico y casi único de lo que en las Vitas Sanctorum Patrum Emeretensium (citadas en adelante $V S P E$ ) se nos anuncia como vida del obispo Masona '.

Lo singular de este episodio es que el ropaje literario que lo envuelve y el modelo literario sobre el que está construido tiene todas las características no de una uita, como generalmente se consideraba, sino de una passio (me refiero siempre a las pasiones literarias, las que $\mathrm{H}$. Delehaye ha llamado «épicas», aunque más de una vez me referiré también a diversas actas de mártires), perspectiva esta desde la que nunca había sido considerado ${ }^{2}$.

Solamente J. N. Hillgarth entrevió algo al significar que "the scene between Leovigild and the Bishop Masona is modelled on the Passiones of martyrs" ${ }^{3}$, pero no entró en mayores detalles. Desde mi punto de

1 Todas las citas proceden de mi edición Vitas Sanctorum Patrum Emeretensium, Turnhout 1992 (Corpus Christianorum, Series Latina 116).

2 J. N. Garvin, The Vitas Sanctorum Patrum Emeretensium, Washington 1946; Carmen Codoñer, "Literatura hispano-latina tardia", en Unidad y pluralidad en el mundo antiguo. Actas del VI Congreso español de Estudios Clásicos, I, Madrid 1986, pp. 435-436 (de la misma autora añádase ahora su análisis de esta obra en Historia de España Ramón Menéndez Pidal, III, España visigoda, II, Madrid 1991, pp. 260261), y César Chaparro Gómez, «Significado de las Vitas Sanctorum Patrum Emeretensium: lectura de sus fuentes", en Humanitas in honorem Antonio Fontán, Madrid 1992, pp. 339-349.

${ }^{3}$ En "Historiography in Visigothic Spain" en $X V I I^{a}$ Settimana di Studio del Centro italiano di Studi sull'alto Medioevo. La Storiografia altomedievale, Spoleto 1970. p. 306. 
vista es todo el conflicto (mucho más allá de la sola escena a la que se refiere Hillgarth) entre Masona y Leovigildo y el retrato de los dos actores principales de este enfrentamiento el que está creado sobre el modelo de las pasiones; el episodio, en suma, abarca desde la aparición en escena del monarca en IV 4-5 (p. 54) a su terrible muerte en IX 1-9 (pp. 78-79).

Es evidente que el propósito del autor de retratar el conflicto entre católicos y arrianos, personificado en las figuras de Masona y Leovigildo, se avenía mejor con el género de la pasión que con el de la vida, porque la pasión dispone de dos personajes que reflejan el enfrentamiento de dos ideales religiosos antagónicos en la era de las persecuciones; de este modo ha sido muy fácil para el autor traducir este conflicto entre paganos y cristianos a este otro entre católicos y arrianos y hacer de Masona el remedo de un heroico mártir y de Leovigildo la caricatura rídicula y anacrónica de un perverso perseguidor. Resulta así también más aleccionador desde el punto de vista didáctico ${ }^{4}$ y cuadra mejor con el carácter apologético que aquí adquiere la obra: los católicos, como los cristianos perseguidos, son los buenos, y los herejes arrianos, como los paganos, son los malos. El autor encontró además y utilizó profusamente un ejemplo muy próximo, la Vita Desiderii del rey Sisebuto, que reproducía el viejo modelo del antagonismo entre el perseguidor y el mártir de las actas y de las pasiones de los mártires. No está de más recordar, por otra parte, como ha hecho J. Fontaine para el caso de la mencionada Vita Desiderii ${ }^{5}$, que éste es también el momento en que se redacta la mayoría de las pasiones de los mártires hispanos que forman parte de nuestro Pasionario Hispánico.

Esto es lo que por las actitudes de los dos protagonistas principales, los tópicos, las fuentes literarias y la lengua deduzco de este singular

Remite en una nota a VI 16-23, pp. 212-6 de la edición de Garvin = VI 66-104, pp. 66-69 de mi edición, es decir, lo que es parte de lo que puede llamarse interrogatorio de Masona, y añade en la misma nota «Cf. also the attempt to kill Masona by mounting him on an untamed horse".

4 Para un público que conocia las pasiones por su lectura pública, aunque la cuestión es discutida (A. Fábrega Grau, Pasionario Hispánico, siglos VII-XI, I, Madrid-Barcelona 1953, pp. 282-286; B. de Gaiffier, "Les lectures des actes des martyrs dans la prière liturgique en Occident. À propos du Passionaire hispanique», Analecta Bollandiana 72, 1954, pp. 134-166; Carmen García Rodríguez, El culto de los santos en la España Romana y Visigoda, Madrid 1966, pp. 73-76; M. C. Díaz y Díaz, "Passionnaires, légendiers et compilations dans le haut Moyen Âge espagnol",, en Hagiographie, Cultures et Sociétés, IV-XII siècles. Actes du Colloque organisé à Nanterre et à Paris, París 1981, pp. 52-53).

5 "King Sisebut's Vita Desiderii and the Political Function of Visigothic Hagiography" en Edward James (ed.), Visigothic Spain: new approaches, Oxford 1980, pp. 118-119. 
episodio, que se destaca de un modo especial dentro del conjunto de la vida de Masona.

Esta óptica tan peculiar con la que el autor retrata el conflicto entre Masona y Leovigildo tiene también la mayor importancia desde el punto de vista histórico: la personalidad de Leovigildo, desde su entrada en escena en IV 4-5 a su muerte en IX 1-9, aparece completamente desfigurada por este tamiz de las pasiones por el que se le hace entrar. Cualquier juicio histórico que se haga (y no se ha hecho precisamente así) sobre su persona a través de la lectura de este texto, al que tanta importancia como fuente se le otorga, ha de partir de estos presupuestos. Es aquí donde precisamente está la causa de la radical diferencia, significada más de una vez (pero no explicada), entre el Leovigildo de Nancto, benévolo y justo, aunque arriano (VSPE III 34 ss., pp. 23-24), y este otro Leovigildo de Masona, implacable y cruel perseguidor.

Para empezar, todos los calificativos aplicados a Leovigildo son los propios de los perseguidores en las pasiones. Leovigildo es ante todo un tyrannus (IV 30, V 1, VI 38, 44, 57, 82, 106, VIII 16) ${ }^{6}$; es impius o impiissimus (VIII 16 y VI 111) ${ }^{7}$; por paradójico que parezca, porque en toda la obra no aparece ni una sola escena de tortura, su nota más característica (siempre, como también ocurre en las pasiones con esta y otras cualidades del perseguidor, en grado superlativo) es la de los jueces romanos en los suplicios infligidos a los mártires, la crueldad (IV 4, VI 118, V 1, VIII 37 crudelissimus; IV 4 seuissimus; IV 30, VI 37 atrocissimus) $^{8}$; es además insanissimus (VI 46, VI 81 , VIII 30$)^{9}$ y profanus (VI 57) ${ }^{10}$.

- Es el calificativo empleado para designar al juez pagano o al emperador perseguidor ya desde Prudencio (más de 15 usos en el Peristephanon) y los epigramas del papa Dámaso (cf. el comentario de J. Fontaine a tyrannus en Sulpice Sévère, Vie de Saint Martin, París 1968, II, p. 525 [Sources Chrétiennes 134]), de uso extendidísimo y obligado en las pasiones.

7 Es el epíteto utilizado para designar a todos los emperadores romanos, hayan ordenado o autorizado persecuciones contra los cristianos y trátese de quien se trate: Nerón, Diocleciano, Trajano, Marco Aurelio, etc. (H. Delehaye, Les légendes hagiographiques, Bruselas $1973_{4}$, p. 21).

${ }^{8} \mathrm{H}$. Delehaye, Les Passions des martyrs et les genres littéraires, Bruselas $1966_{2}$, pp. 178 y $197-206$.

9 Pass. Agnetis 13, 1, Fábrega, p. 179 insanus iudex. Es un calificativo que más de un mártir dedica al juez (H. Delehaye, Les Passions..., p. 191) como, por ej., Pass. Babylae 23, 3-4, p. 201 Tunc Babylas... exclamat: Insane et crudelior omnibus tyranne... La insania (Pass. Cucufatis 8,14, p. 13) y amentia ( $($ Santiago, Mariano y otros" II, Ruiz Bueno, Actas de los Mártires, Madrid 1952, p. 826) del juez pagano (otras veces es llamado insensatus et sine intellectu, de origen bíblico, o insaniens) es de regla en las pasiones.

${ }_{10}$ Pass. Innumer. Caesaraugust. 4, 18-19, Fábrega, p. 373 profane ac sacrilege 
Leovigildo no sólo no está poseído por el diablo (V 4-5 cuius obsedebat pectus truculentior hostis et captiuum in sua dicione tenebat callidissimus serpens) y actúa movido por él (IV 9 consilio diabolico armatus) ", sino que es el diablo en persona (VI 65 acrius infrendere cum dentium stridore contra uirum Dei diabolus cepit $)^{12}$. En realidad, es el diablo, el organizador último de las persecuciones y de las pasiones de los mártires ${ }^{13}$, que ha declarado la guerra a los cristianos y con quien el mártir debe luchar y conseguir la corona de la victoria ${ }^{14}$, quien desata la persecución contra Masona ${ }^{15}$ y mueve todos los hilos de la trama en la persona de Leovigildo o de sus secuaces, el obispo arriano Sunna y el obispo católico impostor Nepope. Estos dos personajes secundarios son tan diabólicos como el propio Leovigildo. También Sunna está tan poseido por el diablo como Leovigildo (V 23-24 addictus predonis funesti artioribus uinculis sauciatusque de eius poculis letalibus) y no sólo ladra rabiosamente como el rey (V 25-26 cepit contra Dei famulum rauidos oblatrare sermones) ${ }^{16}$, sino que silba como una serpiente, símbolo del diablo mismo (V 76-77 quum... ille contra procacioribus uerbis, utpote per ore draconis, insibilaret) ${ }^{17}$; a su vez Nepope es, como Leovigildo,

mentis Datianus; Pass. Vincentii 24, 7, Fábrega, p. 194 Eumorfius quidam... profane mentis (cf. VSPE V, XII 7-8 comites [Arriani] prophani mentibus).

"Pass. Iuliani 21, 2, p. 127 Martianus preses, consilio diaboli armatus; Pass. Felicis, 2, 5, p. 315 proceres ciuitatis... diaboli armati consilio; Pass. Innumer. Caesaraugust. 6, 2, p. 373 (Datianus) diabolico perarmatus spiritu.

12 Cf. Pass. Vincentii 10, 1-2, Fábrega, p. 189 diabolus $(=$ Datianus $)$ fremere cepit, rabidioribus intonare sermonibus, stridore dentium frendere, de donde quizá depende este texto. A lo largo de toda esta pasión, Daciano y el diablo son una misma persona: 6,9 ss., p. 188 Iste (= Datianus) enim ille est uenenatissimus serpens... Iste (= Datianus) ille est quem exigimus e corporibus humanis inuocatione diuina et Christi nomine; 8, 2, ss., p. 189 At ille (Vincentius) subridens ait: «... Ne cesses, diabole, crudelitate qua adspiras... Nolo cesses: insurge, diabole, et toto malignitatis tue spiritu debacchare». Otras identificaciones del juez con el diablo en otros textos, por ej., "Saturnino, Dativo y otros", Ruiz Bueno, p. 977 cum a diabolo per iudicem diceretur; p. 981 qua uoce diabolus (= iudex) superatus "Parce», inquit,..

13 Ya desde la Pass. Perpetuae et Felicitatis 20, 1 Puellis autem ferocissimam uaccam... diabolus praeparauit (A. A. R. Bastiaensen, Atti e Pasioni dei Martiri, Fondazione Lorenzo Valla, 1987, p. 142 y comentario en p. 447).

${ }_{14} \mathrm{Cf}$, por ejemplo, Passio ss. Datiui, Saturnini presb. et aliorum 2 (Pio Franchi de' Cavalieri, Note agiografiche, fasc. 8. ${ }^{\circ}$, Ciudad del Vaticano 1935 , p. $50=$ Ruiz Bueno, p. 972) Temporibus namque Diocletiani et Maximiani bellum diabolus Christianis indixit... exercitus Domini... descendit in proelium non tam contra homines quam contra diabolum pugnaturus (sobre este tema véase J. Daniélou, en Dictionnaire de Spiritualité, Ascétique..., III, col. 180 ss.).

is IV 1-12, pp. 54-55.

${ }_{16}$ Sobre este topos véase más abajo, p. 174 y nota 32.

17 Pass. Theodosiae 16 (Fábrega, p. 248) Vrbanus preses insibilauit uoce serpentis rabidioresque sermones inclamans; Pass. Vincentii 5, 6, ibidem, p. 188 mox inflata uox serpentis insibilat: "Quid agis», inquit, «tu...» (el que habla es Daciano). Cf. también 
profanus (VI 137) y otra marioneta en manos del diablo (VI 137 seruus diaboli) ${ }^{18}$.

En las pasiones ${ }^{19}$ el juez, para tratar de convencer al mártir de que sacrifique a los dioses paganos, monta toda una estrategia de la persuasión: trata primero de convencerlo prometiendo regalos (munera) y los cargos públicos más peregrinos (honores) ${ }^{20}$ y recurriendo a los halagos y buenas palabras (blanditiae, blandimenta, blando colloquio, blandis sermonibus); sólo cuando esta táctica había fracasado pasaba al terreno de las amenazas y las torturas (minae, terrores). El comportamiento de Leovigildo procede de este topos: trata primero de convencer a Masona con halagos y promesas (IV 18-20 cepit supra dictus rex diuersis suasionibus animum eius inlicere forsitan per quacumque occasione posset eum ad sue supprestitionis uoluptatem incurbare); es de suponer que también con regalos, porque Masona los desprecia (IV 21-22 dona et premia ueluti purgamenta respuit) ${ }^{21}$. Cuando ha fracasado con esta táctica, recurre a las amenazas (IV 26-28 Quumque se ille cerneret casso labore deficere, ... cepit multis pulsare terroribus, opinans minis posse concutere quem blandimentis superare nequiuisset; VI 50 cepit minis terroribusque impellere) ${ }^{22}$.

el improperio $O$ uiperosa diaboli lingua! que con variantes mínimas más de un mártir dedica al juez (Pass. Vincentii 13, 1, p. 191; Pass. Cucufatis 6, 10, p. 312; Pass. Felicis 11,2 , p. 323).

${ }_{18}$ Cf. minister diaboli o minister Satanae aplicado al iudex en las pasiones passim (por ej., Pass. Facundi et Primitiui 18, 1, Fábrega, p. 54; Pass. Agathae 9, 9, ibidem, p. 222; Pass. Innumer. Caesaraug. 12, 1, ibidem, p. 376; "Táraco, Probo y Andrónico", Ruiz Bueno, p. 1091). Recuérdese también que en IX 32-33, ya muerto Leovigildo, el diablo (antiquus hostis) vuelve a presentar nuevas batallas per suos ministros, el obispo Sunna y los condes arrianos conjurados para asesinar a Masona.

${ }^{19}$ H. Delehaye, Les Passions..., pp. 186-7.

${ }_{20}$ Pass. Claudi I, Ruiz Bueno, p. 1166 Lysias praeses dixit: Domini nostri imperatores iusserunt christianos uos sacrificare diis, contradicentes puniri; cedentes autem honores et munera polliceri. Otros ejemplos en Pass. Facundi et Primitiui 2, 9-12, Fábrega, p. 47; Pass. Felicis Ger. 8, 7-9 y 11, 11-12, pp. 322 y 323; Pass. Cosmae et Damiani $4,3-4$, p. 350 , etc.

${ }^{21}$ No se puede, por tanto, equiparar, como hace R. Collins («Merida and Toledo: 550-585” en Edward James, ed., Visigothic Spain: new approaches, Oxford 1980, p. 212), el ofrecimiento al abad africano Nancto por parte de Leovigildo de una porción de tierra del fisco real (VSPE III 34 ss.) con este otro of recimiento de regalos; aquél puede haber sido histórico, éste es un topos literario procedente de las pasiones.

${ }^{22}$ Los textos son una adaptación de diversas pasiones: Pass. Agnetis 8, 2-3, Fábrega, p. 178 quumque omnis sermo eius casso labore deficeret $+7,1-2$, p. 177 Et primum quidem blandis eam sermonibus secretius prouocat, dehinc terroribus pulsat + Pass. Iuliani 35, 4-5, p. 133 Audiens hec preses Martianus fremuit ut leo extimans pena terreri quos blandimentis superari non ualuit.

La antítesis entre minae (otras veces terrores, véase nota 24) y blanditiae o blandimenta, que ya aparece en Cicerón (Tusc. V 87 minis aut blandimentis corrupta; Mur. 
Si Leovigildo es un perseguidor, el comportamiento de su antagonista Masona es en todo momento el de un mártir: no se deja halagar por las promesas (IV 20-21 Ille uero suasiones multas callidas contemsit), rechaza (ya lo hemos visto) los presentes of recidos por Leovigildo ${ }^{23}$ y de la misma manera que no ha cedido a los halagos, tampoco se arredrará ante las amenazas de tortura (IV 28-29 Sed uir sanctus nec terroribus frangitur nec blandimentis suaditur) ${ }^{24}$ en su heroica confesión de fe (IV 22 fidem catholicam uiriliter prorsus uindicauit); tampoco permanece impasible ante las amenazas, sino que hace oír su voz y arremete contra el tirano con los reproches que merecía (IV 23 nec tamen contra perfidiam tacere maluit; IV 15-17 ipsi insuper Arriano regi exprobrauit ut debuit eiusque a se perfidiam dignis increpationibus repulit) ${ }^{25}$.

La confrontación directa entre el juez y el mártir forma parte de todas las pasiones. En las $V S P E$ el encuentro entre Leovigildo y Masona tiene lugar en Toledo, tras la detención de Masona en Mérida. A decir verdad, el interrogatorio propiamente dicho no discurre por los términos estereotipados de toda pasión; como es evidente, no hay lugar a las largas discusiones doctrinales entre el mártir cristiano y el juez pagano: en este caso, una vez que la posibilidad de conversión de Masona a la herejia arriana queda frustrada (VI 38-45), la disputa se centra en la posesión de la túnica de santa Eulalia.

Pero sí son propias de las pasiones y tópicas las actitudes de los dos protagonistas. La alegría de Masona es la del mártir en el momento de su detención (si es que el mártir no se presenta «alegremente» por propia iniciativa ante el juez), a lo largo de todo el proceso y en el momento de su condena (VI 35 ylari uultu, VI 102 cum exultatione magna) ${ }^{26}$;

44 non minae magis quam blanditiae), es poco menos que un lugar común en la literatura del martirio y de las pasiones: Prud. Perist. XIV 15-17 Temptata multis nam prius artibus / nunc ore blandi iudicis inlice / nunc saeuientis carnificis minis; Cypr. epist. X 2 non blanditiae decipiant, non minae terreant; Pass. Felicitatis I, Ruiz Bueno, p. 294 Publius... prefectus urbis... blando colloquio ad sacrificium eam prouocans, minabatur poenarum interitum...

${ }^{23}$ Cf., por ej., Pass. XL martyrum 4, 8-9, Fábrega, p. 145 iudex crudelissimus... blandimentis extimabat eos seducere et persuasione uerborum et promissis regalibus et diuitiis temtabat. Qui uero non consentientes ad ea...

${ }^{24}$ Pass. Agnetis 7, 4, p. 178 Christi uirgo nec blandimento seducitur nec terrore concutitur; Pass. Felicitatis I, Ruiz Bueno p. 294 Cui Felicitas dixit: Nec blandimentis tuis resolui potero nec terroribus tuis frangi; Ambr., de uirg. I 2, 9, Migne 16, col. 191 quanto terrore egit carnifex ut timeretur, quantis blanditiis ut suaderet!; Pass. Fac. et Prim. 12, 2-3, Fábrega, p. 51 (iudex) direxit eis de epulis... dicens: "Forsitan uel blandimentis adquiescunt, si terroribus non pauescunt".

${ }^{25}$ Sobre este topos de la soltura de lengua de los mártires véase infra, p. 173 y nota 27.

${ }^{26}$ Pass. Perp. et Felic. 6, 6, Bastiaensen, p. 124 hilares descendimus ad carcerem (y comentario en p. 426); 18,1, ibidem, p. 138 processerunt de carcere in amphithea- 
es la misma actitud que mantiene a lo largo del debate con Sunna (V 56 cum alacritate, V 62 uultus sui iucunditate). La virtud más notable de Masona en todo el proceso es la típica de los mártires, la constancia (IV 13 Quumque... constantissime responderet, VI 46 Cuius constantia magis magisque permotus insanissimus rex, VI 81 Ob cuius constantia, VI 102 constanter ayt); Masona se muestra impertérrito, atrevido y arrogante, con el porte heroico y valiente del mártir ante las amenazas del juez y el desparpajo y la soltura de lengua de los mártires, impropia del papel de víctima que juega (VI 72 Exilium mici minaris? Conpertum tibi sit quia minas tuas non pertimesco, VI 85 milex Dei ita inperterritus respondit: "Iam dixi tibi semel et iterum quia minas tuas non formidabo...") ${ }^{27}$; hasta en un momento dado sale a relucir que a los ojos de Leovigildo es, como los antiguos mártires lo eran a los ojos de los jueces romanos, un biothanatus (VI 74-75 Cui ille ayt: "Et in quo loco Deus non est, biothonate?») ${ }^{28}$.

No hay suplicios, mas la idea revolotea por el ambiente: a Masona, de quien no nos consta por el texto que fuera torturado, se le escapan unas palabras con las que los mártires cristianos incitan a sus verdugos a proseguir con los suplicios (VI 86-87 Sed quidquid ualet mens tua peruersa amplius aduersum me excogitet $)^{29} \mathrm{y}$, cuando Leovigildo dice diuersis suppliciis faciam diuaricari membra tua $(\mathrm{VI}, 84)^{30}$, habla como un

trum... hilares; "Montano» 13, Ruiz Bueno, p. 812 Erat illic uidere martyres Christi felicitatem gloriae suae uultus hilaritate testantes; el cliché hilari uultu se lee passim (Acta Maximiliani 3, 3, Bastiaensen, p. 244; Pass. Vincentii 16, 5, Fábrega, p. 191; Pass. Euphimiae 10, 10 y 19, 7, pp. 341 y 344, etc.).

27 Pass. Romani 4, 12, Fábrega, p. 19 minas tuas minime pertimesco; Pass. Andreae 9, 21, p. 63 me putas minas tuas posse formidare; Pass. Eulaliae 11, 2-3, p. 72 Non timeo minas tuas; 16,15, p. 76 minas et supplicia tua non pertimesco (véase también H. Delehaye, Les Passions..., p. 191).

28 Es un término despectivo aplicado por los paganos a los mártires cristianos: Pass. Romani 19, 1, Fábrega, p. 23 Asclepiades prefectus dixit: "Biothenate et omni sacrilegio plene»; Pass. Geruasii et Prot. 11, 2, p. 282 cui et (comes Astacius) dixit: «... noli biothanatus fieri, sicut et frater tuus Geruasius»; "Sinforosa» IV, Ruiz Bueno, p. 262 et imposuerunt Pontifices nomen loco illi "Ad septem Biothanatos». También se aplica a Cristo mismo (Gregentius Tapharensis, Disputatio cum Herbano Iudaeo 2, Migne 86, col. 657 b). Puede verse también J. H. Waszink en RAC II, s.u. biothanati, cols. 391-394 (en particular 393).

La etimología isidoriana (Orig. X 31) de esta palabra, bis mortuus (otros codd. ui mortuus), la misma que recogen los glosarios (G. Goetz, Corp. Gloss. Latin., IV, p. 592, 43; añádanse las glosas del pasionario de Cardeña, Fábrega, p. 394 b), es un disparate.

${ }^{29}$ Cf. Pass. Andreae 9, 21-22, Fábrega, p. 63 quicquid tibi uidetur in suppliciis magis excogita.

${ }^{30}$ Cf. Pass. Vincentii 12, 6, Fábrega, p. 190 iuncturas et conpages diuaricatas diuortio tormentorum; 17,8 , p. 192 diuaricate preterea distentum roborem, quodadusque discerpi pene artus possint, ut per singula membra... 
juez pagano pensando en el suplicio del equuleus, lo que no deja de ser, como mínimo, ridículo.

Si tópica es la actitud de Masona, tópicas son también la exasperación y la rabia de Leovigildo ante la firmeza del "mártir» (IV 26 raptus in furore, VI 57 in furore uesanie uersus) ${ }^{31}$; Leovigildo no habla, ladra como un perro rabioso (VI 42 rauidus canis oblatrabat, VI 46-48 rex... cepit rauido ore rauidioribus aduersus Dei famulum infrendere latratibus, VI 107 sententiam oblatrauit) ${ }^{32}$, furioso y loco en su crueldad como una bacante (VI 78-79 quantum tu in me crudelius fueris debaccatus) ${ }^{33}$; tratando de torturar a Masona se tortura a sí mismo y sufre más que el propio Masona (VI 81-82 Ob cuius constantia maiori supplicio pessime mentis sue insanissimus tirannus interius afflictus, felle et amaritudine nimia permotus), como Daciano cuando se ensaña con Vicente ${ }^{34}$.

En el desarrollo del interrogatorio con Leovigildo no faltan tampoco los prodigios, por los que Dios manifiesta su asistencia al mártir y confunde a sus verdugos. En el curso del proceso se suceden dos. En el primero los truenos con el cielo despejado (milagro que procede de la Passio Agnetis ${ }^{35}$ ) sirven a Masona para proclamar: Si regem, ecce regem

${ }^{31}$ Pass. Fac. et Prim. 12, 6, Fábrega, p. 51 (preses) comotus ira uesanie; 17, 1, p. 53 uesano furore arreptus. Los clichés ira accensus (Pass. Columbae 6, 1, p. 117; Pass. Cucufatis 3, 7, p. 310), ira repletus (Pass. Aciscli 14, 1, p. 16; Pass. Eulaliae Barc. 7, 1, p. 236), furore accensus (Pass. Felicis 15, 1, p. 318; Pass. Fausti 2, 8-9 y 7, 1, p. 346 y 348; Pass. Cosmae et Dam. 14, 6, p. 352), furore repletus (Pass. Adriani 7,1 y 9,18 , p. 268 y 269; Pass. Cucufatis 6, 6 y 9, 1, p. 312 y 313) y similares, referidos al juez, recorren las pasiones (véase también $\mathrm{H}$. Delehaye, Les Passions..., p. 178).

${ }^{32}$ Identificación del perseguidor (o los perseguidores) con un perro rabioso en Pass. Thyrsi 3, 13, Fábrega, p. 202 ut rabidus canis; en Pass. Vincentii 6, 5 ss., p. 188 "Quid submurmuras", inquit episcopo suo Vincentius sanctus..., "et contra canem leuiter musitas (asi debe leerse y no musitus por una mala lectura del editor o confusión del escriba entre $u$ y $a$ en la minúscula visigótica); exclama in magna uirtute, o christicola, ut conterrita rabies, que contra sanctum Dei mysterium latrat, ... frangatur!); en Pass. Dorotheae 5, 4 ss., p. 227 se encuentra esta ingeniosa argumentación: Hii qui Deum timent, homines rabidos non timent. Hoc enim faciunt, quod canes rabidi, laniant homines innocentes: et quia ratio in illis nulla est, insaniunt, deseuiunt, irascuntur et latrant et suis morsibus uulnerant transeuntes. Cf. también rabies paganorum y rabies persecutionis que aparecen passim.

${ }^{33}$ Pass. Iuliani 57, 7, Fábrega, p. 141 diuersis tormentis in uos debacchabor; Pass. Felicis 18, 2, p. 319 Sanctus Felix dixit: "Bacchare in me, miser, et adde tormenta..."; Pass. Vincentii 8, 9, p. 189 toto malignitatis tue spiritu debacchare; 9, 1-2, p. $189 \ldots$ Datianus cepit... illo furore bacchari; 19, 12, p. 193 furor bacchantis; 21, 5, p. 193 nouis suppliciis debacchabor.

${ }_{34}$ Pass. Vincentii 10, 1-3, Fábrega, p. 189 ... diabolus (= Datianus) fremere cepit... et in suis amplius deseuire ut, dum martyrem Dei lacerat, se ipsum potius laceraret; y como también los propios verdugos al servicio de Daciano: ibidem, 10, 7-8, p. 190 putasses potius ipsos inter martyris sancti tormenta torqueri (putans se en Fábrega, putasses, lección de los pasionarios de Toledo y Tuy, en Pilar Riesco, El Pasionario Hispánico, Universidad de Sevilla 1989, tesis doctoral en microfichas, p. 150).

${ }_{35}$ VI 99-100, p. 68 Dum hec et his similia loquerentur et esset multa celi serenitas, 
quem timere oportet, nam non talem ( = talis) qualis tu es (V 102-104, p. 69); este desafio arrogante al monarca arriano es un eco del conflicto entre el estado romano y los cristianos del que dan cuenta numerosas actas y pasiones: Masona, como los antiguos mártires en su negativa a acatar los edictos imperiales y sacrificar a los dioses (o al emperador), no reconoce más rey, emperador y señor que Dios, el único y verdadero soberano, rey de reyes y señor de los señores ${ }^{36}$.

Hay un segundo episodio milagroso, que debe ser interpretado en el contexto de las pasiones, por el que se pretende equiparar a Masona con los antiguos mártires. No tiene sentido desde el punto de vista del derecho que Masona, que ya ha sido condenado al exilio, sea expuesto a una muerte segura haciéndolo montar en un caballo salvaje (VI 111 ss., p. 69). En este episodio está presente el recuerdo, referido en multitud de pasiones, de tantos mártires condenados ad bestias, cuyos pies lamen las fieras, convertidas para confusión de los paganos (y en este caso de los arrianos) en mansos corderos. El texto en gran parte depende de otro de Gregorio Magno, pero el contexto en que este último aparece es completamente diferente y nada martiriológico ${ }^{37}$. Ha sido el autor quien lo ha adaptado a estas circunstancias: la damnatio ad bestias se desarrolla en el curso de un munus, del que el martirio forma

maiestas diuina celitus fragore magno repente intonuit ita ut... es igual a Pass. Agnetis 26, 1-3, Fábrega, p. 181 et quum nimia esset celi serenitas, tante coruscationes tantaque fulgura ac tronitua extiterunt ut... (dicho sea de paso, llamo la atención sobre el hecho de que del texto citado de la Passio Agnetis depende un pasaje de la Translatio ss. Fructuosi, Augurii et Eulogii, publicada como apéndice a "Gli Atti di S. Fruttuoso di Tarragona", pp. 129-199, por Pio Franchi de' Cavalieri en Note agiografiche, fasc. $8 .^{\circ}$, Ciudad del Vaticano 1935, p. 198, que dice Et cum nimia esset celi serenitas, subito coruscus apparuit tronituaque mugire coeperunt).

${ }^{36}$ Lo que, ya desde muy antiguo (Acta mart. Scilitan. 6, Bastiaensen, p. 102), más de un mártir refiere a los jueces recordándo las palabras de las Escrituras: Dios es solus regum omnium terrae que hizo el cielo y la tierra (IV Reg. 19, 15), Rex regum et Dominus dominantium (I Tim. 6, 15; Apoc. 17, 14; 19, 16). En las pasiones literarias constituye poco menos que un lugar común: Pass. Romani 3, 5, Fábrega, p. 19 Nos regem colimus Deum, uos uero corruptibiles reges habetis; Pass. Facundi et Primitiui 6, 6, p,. 49 Nos, o iudex, quotidie offerimus sacrificium magno regi Domino Iesu Christo inmortali Deo. Propterea non timemus regem mortalem; Pass. Eulaliae Barc. 5, 14, p. 235 Ego sum Eulalia, ancilla Domini mei Iesu Christi, qui est rex regum et dominus dominantium; Pass. Dorotheae 4, 7, p. 227 Videndum ergo est cui imperatori obtemperari debeamus, terreno an celesti, mortali an inmortali, Deo an hominibus; Pass. Euphimiae 4, 7-8, p. 339 Notum tibi sit, proconsul, quod nos seruimus magno et perpetuo regi, etc.

${ }^{37}$ En Gregorio Magno, por el contrario, aparece lo que podría considerarse una auténtica damnatio ad bestias (el obispo Cerbonio expuesto a un oso salvaje por el rey Tótila: Dial. III 11, 1-3, ed. A. de Vogüé, París 1979 [Sources Chrétiennes 260], pp. 292-294), que podia haber sido utilizada por el autor para este episodio, pero de la que no se ha valido lo más mínimo, prueba de que ha hecho una adaptación hasta cierto punto original del otro. 
parte como un número más de ese spectaculum ${ }^{38}$, y eso es lo que precisamente espera el rey Leovigildo, un gran espectáculo (VI 118-120 rex crudelissimus... expectabat ut ei uir sanctus de equo casurus ingens expectaculum [ = spectaculum $]$ preberet $)$; Masona antes de montar en el caballo hace la señal de la cruz (121 edicto [ = edito] uexillo crucis) como, por ejemplo, Teodosia antes de salir a la arena y enfrentarse con las fieras salvajes se arma con el "estandarte» de la cruz $^{39}$; es típico de estos episodios de las pasiones (y no está en Gregorio Magno), en tercer lugar, el motivo de la transformación de los animales salvajes en corderos (122-123 ascendit equum ferocem, quem ei Dominus uelut agnum mansuetissimum reddidit) ${ }^{40}$; puede añadirse la sorpresa y la admiración de las masas ante las que suelen desarrollarse tales prodigios, lo cual también está presente (126-128 Quumque hoc miraculum omnes cernerent, obstupescentes ualde admirati sunt. Nam et ipse rex in magna conuersus est admiratione).

Es también dentro de este contexto de las pasiones y de los modelos literarios creados por ellas donde debe ser analizada una fuente en particular de las VSPE; se trata de la Vita Desiderii del rey Sisebuto ${ }^{41}$.

En la dependencia de las VSPE de la Vita Desiderii han llamado siempre la atención dos hechos: la utilización masiva de pasajes de esta vida y la concentración de estos préstamos casi única y exclusivamente

${ }^{38}$ Pass. Perp. et Felic. 19, 3 (Bastiaensen, p. 140) Itaque in commissione spectaculi...; 21, 2 (p. 144) Et statim in fine spectaculi...; a partir de aquí, ya sin esta connotación histórica y como simple motivo literario, el martirio es un "espectáculo", a pesar de que no haya espectadores: de los santos Justo y Pastor, que murieron decapitados en un descampado "lejos de la ciudad" (6, Fábrega, p. 330), se nos dice $(2,12$ y 3,4 , p. 329) que... ad spectaculum proprii martyrii alacri deuotione cucurrerunt y ... pro hoc ad spectaculum uenerunt. No obstante, también puede tener su influencia la imagen de S. Pablo (I Cor. 4, 9; y también Hebr. 10, 33), forjador de tantísimas metáforas de las pasiones, como genialmente intuyó el autor de la Pass. Innumer. Caesaraug. 9, 11, p. 375 ita ut crederes totius funditus migrare multitudo populorum ciuitatis ad spectaculum gladii furientis, sicut ait egregius predicator: «Spectaculum facti sumus huic mundo, angelis et hominibus").

El motivo llega hasta la Historia Compostelana I, II 2 (ed. Emma Falque, CC CM 70, p. 10), cuando el obispo Ataúlfo, acusado de sodomia y condenado a enfrentarse con un toro, llega ... quasi inexpugnabilis athleta Dei ad martirium, ubi spectaculum erat.

39 Pass. Theodosiae 30, 3, p. 253 Videns tantam multitudinem ferarum uexillo crucis armat pectus suum et frontem (otros ejemplos en Pass. Aciscli et Victoriae 8, 3-4, p. 14; en Pass. Iuliani 19, 19 y 58, 19, pp. 127 y 142, y en Pass. Facundi et Primitiui 13,13 , p. 52, donde los mártires, a los que se pretende envenenar, armantes frontes suas uexillo crucis comederunt et nicil mali senserunt).

${ }^{40}$ Pass. Theodosiae 31, 5-6, p. 253 leo... conuersus in oue; Pass. Xysti 4, 6, p. 332; «Táraco, Probo y Andrónico», Ruiz Bueno, p. 1136.

41 Todas las citas corresponden a la edición de Juan Gil en Miscellanea Wisigothica, Sevilla 1972, pp. 53-68. 
en la vida de Masona (estadísticamente, según mi aparato de fuentes, de 40 préstamos 32 pertenecen a esta vida); pero, puestos a dar números, yo llamaría la atención sobre un tercero, quizá mucho más significativo: de esos 32 préstamos 29 se concentran en el texto que estoy comentando. Está claro que tiene que ser por algo. Recientemente César Chaparro ha ensayado una explicación que, dicho sea con todo respeto, no comparto ${ }^{42}$. Todo adquiere sentido, si se analiza esta fuente dentro de las coordenadas de las pasiones y de cuanto vengo considerando y consideraré. La Vita Desiderii es una uita, pero también una passio ${ }^{43}$ : el enfrentamiento entre el obispo Desiderio de Vienne con los reyes francos Teodorico y Brunegilda, a consecuencia del cual es primero exiliado y más tarde martirizado. Presenta unas líneas argumentales comunes con las VSPE: enfrentamiento de los obispos con los monarcas, exilio, elección de un obispo impostor, vuelta del exilio a petición del rey por temor al juicio de Dios, castigo y muerte del perseguidor. Pero mucho más importante es el espíritu que anima las dos obras y la cuestión de fondo que subyace en ambas: el conflicto entre el obispo y el rey, que en el caso de la Vita Desiderii a juicio de Sisebuto desemboca en un verdadero martirio, evoca el viejo conflicto entre el perseguidor y el már$\operatorname{tir}^{44}$. El autor de las $V S P E$ ha utilizado, por tanto, todos esos puntos comunes de la trama ${ }^{45}$; ha añadido el motivo de los perseguidores y de

${ }^{42}$ Citado en la nota 2 , p. 348. Básteme significar, como se desprende de lo que llevo dicho, que el antagonista de Masona no es el obispo arriano Sunna, sino el rey Leovigildo, "tirano" frente a "mártir».

${ }^{43} \mathrm{O}$, si se prefiere, como quiere J. Fontaine (citado en nota 5, p. 102) y el propio autor se preocupa de significar (14-15, pp. 61-62 Ista sane... de bita eius dixisse sufficiat. Nunc de passionibus eius, qualiter sanctam animam omnipotenti Domino consignauit, ... expediam), vida y pasión según el modelo de la Vita Cypriani del diácono Poncio.

Aparte de esto, ¿nadie ha reparado en que la Vita Desiderii es una biografia escrita per species al más puro estilo de Suetonio con las transiciones de un "aspecto" a otro perfectamente marcadas: 6, p. 57 sufficienter, ut opinor, de gratia sanitatum sermo generalis emicuit. Sed ne... studui; 8, p. 58 de cuius detestabili exitu calamo pingente continuata narratione notaui; 9, p. 58 Quid de illam iniuste Iustam et iuste dicam iniustam...?; 12, p. 60 tria de eius uirtutibus... enarranda institui; 14-15, pp. 61-62 Ista sane... de bita eius dixisse sufficiat. Nunc de passionibus eius, qualiter sanctam animam omnipotenti Domino consignauit, ... expediam; 19, p. 66 Ergo sicut uitam, uirtutes et eius granditer gloriosum finem descripsimus, restat ut exitia perditorum obitumque narremus; 22, p. 67 ... terminum finemque ponamus?

44 Véase J. N. Hillgarth, citado en nota 3, pp. 286-287, y J. Fontaine, pp. 118119, que descubre en la caracterización de los "perseguidores» de la Vita Desiderii influencias del Peristephanon de Prudencio y Pasiones de mártires hispanos.

${ }^{45}$ En el regreso del exilio de Masona (VSPE VIII 26 ss.), que depende en todo del regreso del exilio de Desiderio (Vita Desiderii 10, 4 ss.), se añade en las VSPE (VIII 14-25, p. 74) un elemento local importante que no quiero olvidar: la intervención milagrosa de la virgen Eulalia y el castigo vengador (gloriosa uirgo iniurias serui 
sus cómplices poseídos por el diablo y en general todos los episodios demoníacos, comunes, por lo demás, a cualquier pasión y casi, por así decirlo, patente del género ${ }^{46}$; que haya utilizado algún otro pasaje es meramente circunstancial o fruto de una hábil adaptación ${ }^{47}$ con mejores resultados a veces que en el original, como, por ejemplo, cuando trasplanta el retrato plural e impersonal de la horda de verdugos que martiriza a Desiderio (Vita Desiderii 18, 2-7, p. 65) a la sola figura del obispo arriano Sunna caracterizándolo brillantemente ${ }^{48}$ como personaje malvado, un engendro por dentro y por fuera, o sea, malo y feo, un verdadero antihéroe ${ }^{49}$. ¡Demasiadas coincidencias con la vida de Masona y el mismo modelo de protagonistas de las pasiones (el mártir y el perseguidor), que tenía en mente el autor de las VSPE, mucho más cer-

sui seuerissima uindicauit ultione) infligido a Leovigildo al que Eulalia azota mientras duerme; este motivo responde al topos del castigo del perseguidor y da una doble satisfacción a los lectores: es la venganza de Eulalia, mártir ella misma, cuya reliquia más preciada (su túnica) trata de usurpar Leovigildo, y es la venganza del "mártir» Masona (sobre el tema del castigo de los perseguidores véase $\mathrm{H}$. Delehaye, Les Passions..., pp. 217-218, y más adelante a propósito de la muerte de Leovigildo; recuérdese también, por ejemplo, que Eulalia de Barcelona [8, Fábrega, p. 236] pide a Dios el castigo de sus enemigos recitando el salmo 53, 6-9 [Deus adiuuat me... Redde mala inimicis meis et in ueritate tua disperde illos... quoniam... super inimicos meos respexit oculus tuus] y las llamas se volvieron contra sus verdugos).

46 Véase supra, p. 170 y notas 13 y 14.

${ }^{47} \mathrm{La}$ sentencia de la condena a muerte de Desiderio se convierte en la sentencia de la condena al exilio de Masona; el llanto del pueblo de Vienne por la muerte de su obispo (que además puede ser un lugar común: Sulp. Seu. Epist. III 10; Pass. Fructuosi 4, Fábrega, p. 184) se transforma en llanto del pueblo de Mérida por el exilio de su obispo, etc.

48 VSPE V 8-19, pp. 56-57 (doy el texto de mi traducción, que próximamente será publicada) «... (Leovigildo) para provocar tumultuosas rivalidades y la alteración del santo y de todo su pueblo nombró obispo de la facción arriana en aquella ciudad a un hombre pernicioso, defensor a toda costa de la maldad arriana. Su nombre era Sunna, un hombre, en efecto, promotor del fatal dogma, funesto y de una fealdad repulsiva, frente sañuda, ojos amenazadores, aspecto aborrecible y porte espantoso. Era de mente perversa, carácter depravado, lengua mentirosa, palabras blasfemas, externamente presuntuoso, internamente vacío, por fuera altivo, por dentro vano, exteriormente engreido, interiormente carente de todas las virtudes, un engendro en ambos sentidos, pobre en bondades, rico en maldades y un candidato espontáneo a la muerte eterna».

49 De la misma manera que los santos y santas, lo mismo que los héroes y heroinas de la novela griega (Quintino Cataudella, "Vite di Santi e Romanzo", en Letterature comparate: problemi e metodo. Studi in onore di Ettore Paratore, II, Bolonia

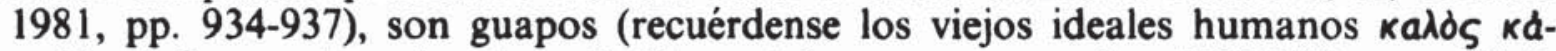
yađós y forma uirtutei parisuma). Como tales aparecen en las VSPE Masona (II 5, p. 48 habitu magni decoris pulcrificatus), pero especialmente Renovato (XIV 19-21, p. 100 Erat enim procerus corpore, forma prespicuus, statura decorus, obtutu gratus, uenusto uultu, decora facie nimiumque admirabilis aspectu, pero, como el autor piadosamente recalca, quamuis extrorsus habitus sui esset gloria decoratus, introrsus pulcrior habebatur lumine sancti Spiritus inlustratus). 
cano en el tiempo y mucho más próximo en la geografía que el recuerdo difuso del mártir y del perseguidor de la era de las persecuciones como para no ser aprovechado! Para un pobre diácono semiletrado de Mérida la Vita Desiderii suponía la evidencia inmediata, garantizada además por una «autoridad» del prestigio intelectual del rey Sisebuto a los ojos de sus contemporáneos ${ }^{50}$, de que los antiguos modelos de las pasiones podían ser todavía vigentes.

El vocabulario del texto es el vocabulario de las pasiones. Ya me he referido a parte de él: minae, terrores, blanditiae, supplicia, tyrannus, impiissimus, crudelissimus; añádanse palabras muy específicas aprendidas en la lectura de las pasiones (como las ya comentadas biothanatus, diuaricare o debacchor) y todo el lenguaje heroico de las pasiones, lleno de metáforas militares: militem Xpi (VI 8-9), milex [sic] Dei (VI 85), prelia (IX 33), congressio (IV 29 forti congressione aduersus atrocissimum tyrannum dimicans pro defensione iustitie persistebat inuictus; V 45-46 alternisque congressionibus dimicantes), uexillum crucis (VI 121), triumphum (V 48 triumphum brabii); súmense, en fin, ciertas expresiones (VI 16-17 suisque obtutibus presentare deberet; VI 36-37 Quumque... atrocissimi tiranni conspectibus adstitisset; VI 66 quum eius obtutibus sisteretur $)^{51}$ y algún tecnicismo jurídico muy antiguo que sólo se lee en las actas de los mártires y en las pasiones, al que luego me referiré.

La verdad es que la jerga de las pasiones aflora por toda la obra, venga o no a cuento, y no sólo en este espisodio ${ }^{52}$. Tiene su gracia ver al obispo hereje Sunna, al que antes se nos ha descrito como un dechado de maldades, con la misma obstinación de un mártir (XI 70 mentem

${ }^{50}$ Cf. Isid. Hist. Goth. 60 (Sisebutus) Fuit autem eloquio nitidus, sententia doctus, scientia litterarum ex parte inbutus.

sl Son las fórmulas utilizadas en las pasiones para enfrentar cara a cara al mártir con el juez: Pass. Facundi et Prim. 5, 1-2, Fábrega, p. 48 iussit eos (Facundum et Primitiuum) suis conspectibus sisti; Pass. Columbae 2, 5, p. 116 iussit eam suis conspectihus presentari; Pass. Iuliani 33, 1-2, p. 132 Quumque eius aspectibus sisterentur; 40, $2-3$, p. 135 iubet sanctum Iulianum... eius conspectibus sisti; 53, 3, p. 140 Quumque eius aspectibus presentarentur; Pass. Felicis 10, 1, p. 323 Sistitur... Felix Rufini conspectibus; Pass. Cosmae et Damianis 10, 1-2-, p. 351 Iussit eos adstare in conspectu suo.

${ }^{52}$ La rara expresión de II 24 ergastulisque trudi (hasta ahora el texto habia sido editado como tradi) ha de proceder del in carcerem trudi de las actas y pasiones de mártires: "Félix de Tibiuca», V, Ruiz Bueno, p. 962; "Saturnino, Dativo y otros", IX y XIII, ibidem pp. 981 y 987; Pass. Andreae 8, 1, Fábrega p. 62; Pass. Leocadiae 4, 16, p. 67; Pass. Felicis 11, 2, p. 317. Compárese tambièn con Prudencio, que ha utilizado actas de mártires y pasiones: Perist. V 238 lugubre in antrum truditur; X 1107 trudi in tenebras noxialis carceris; XIV 25 in lupanar trudere publicum. También se lee in ima carceris trudi (Pass. Adriani 24, 2-3, Fábrega p. 274) e incluso in carceris ima retrudi (Pass. Iuliani 35, 5, p. 133). 
obstinatam pertinacemque $)^{53}$ dispuesto a morir por su fe, la que ha mantenido desde su más tierna infancia (XI 67-69... aut ritu quo uixi uiuebo aut pro religione in qua nunc usque ab ineunte etate mea permansi libentissime moriar $)^{54}$. Pero el colmo de los despropósitos es contemplar al duque Claudio y al propio Masona a punto de morir degollados a manos de los perversos arrianos nada más y nada menos que con la eufemística fómula que utilizaban los procónsules romanos para condenar a la decapitación, como a cualquier otro ciuis Romanus, a los mártires cristianos (X 56 gladio animaduerti) ${ }^{55}$.

No falta, en fin, el topos del castigo de los perseguidores ${ }^{56}$. La muerte de Leovigildo (IX 1-9) ${ }^{57}$ tiene todos los tintes ejemplares y vengati-

${ }^{53}$ Que es precisamente el reproche que hacían los paganos a los cristianos: cf. Plin. Epist. X 96, 3 Neque enim dubitabam... pertinaciam certe et inflexibilem obstinationem debere puniri, texto que guarda un sorprendente paralelismo con el de las VSPE (la pertinaciam et... obstinationem de Plinio se corresponde con la mentem obstinatam pertinacemque de las VSPE), aunque la idea de la pertinacia y obstinatio de los mártires cristianos aflora por todas partes.

${ }_{54}$ Cf. Pass. Adriani 10, 9, Fábrega, p. 269 libentissime enim cum eis moriar; "Crispina», Ruiz Bueno, p. 1143 pro fide mea... libenter patior; «Ireneo», ibidem, p. 1028 Deum habeo quem a prima aetate colere didici; «Felipe», ibidem, p. 1072 me necesse est tenere quod didici et in perpetuum seruare quod colui (cf. VSPE IV 13-15, p. 55 Quumque... [Masona] regi mandaret numquam se ueram fidem relinquere quam semel agnouisset).

"s Es un tecnicismo del lenguaje jurídico: Th. Mommsen, Römisches Strafrecht, Graz 1955 (= Leipzig 1899), pp. 911 y 924, y Giuliana Lanata, Gli Atti dei martiri come documenti processuali, Milán 1973, p. 144.

La fórmula, de la que el único ejemplo recogido en el ThlL, s.u. animaduerto, es Vlp., Dig. XLVIII 19, 8, 1 (también aducido por Th. Mommsen, o.c., p. 924, nota 2, que cita además Lact., Mort. pers. XXII 3 animaduersio gladii), aparece en actas proconsulares, algunas unánimemente reconocidas como auténticas, y a partir de aqui ha debido llegar a las pasiones literarias. Citaré algunos ejemplos que he reunido en mis lecturas: Act mart. Scilitan. 14 Saturninus proconsul decretum ex tabella re(itauit: "Speratum... gladio animaduerti placet" (Bastiaensen, p. 102); Acta Cypriani 3, 6, (en sus dos recensiones, ibidem, pp. 216 y 226); Acta Maximiliani 3, 1 (ibidem, p. 242); "Marcelo" II (D. Ruiz Bueno, p. 956); "Félix de Tibiuca" V (ibidem, p. 963); "Euplo» III (ibidem, p. 1055); "Crispina» IV (ibidem, p. 1146); Pass. Romani 14, 6 (Fábrega, p. 22); Pass. Eugeniae 38, 2 (ibidem, p. 96, donde gladii anima aduerteretur encubre el correcto gladio animaduerteretur); Pass. Iuliani 28, 6 (ibidem, p. 130); Pass. Theodosiae 27, 1-2 (ibidem, p. 252); Pass. Cypriani 6, 12 (ibidem, p. 337: se trata de la segunda recensión de los Acta Cypriani en la edición de Bastiaensen).

Por conducto de las VSPE la fórmula llega hasta la Historia Silense 4 (ed. J. Pérez de Urbel y A. González Ruiz-Zorrilla, Madrid 1959, p. 117). Garvin (o. c., p. 35, nota 12) ha dado en letra cursiva el texto de la Historia Silense dependiente de $V S P E$ V, XII, mas ha de añadirse el gladio animaduertit de la Historia Silense procedente de aquí.

${ }^{56}$ H. Delehaye, Les Passions..., pp. 217-218 (véase supra, nota 45).

${ }^{57}$ Leovigildo falleció de muerte natural: Isid. Hist. Goth. 51 defunctus propria morte; Gregorio Magno (Dial. III 31, 7) dice simplemente post cuius mortem Reccharedus..., pero el autor de las VSPE, que repite el texto de los Diálogos, siguiendo el topos aquí analizado intercala crudelissimam entre cuius y mortem (IX 10) y habla de 
$\operatorname{vos}^{58}$ que acompañan a la muerte de los perseguidores; por eso precisamente su muerte es la suma de los castigos trágicos de dos de ellos, Teoderico y Brunegilda, los perseguidores del mártir Desiderio, en un buen ejemplo de contaminación con alguna aportación personal ${ }^{59}$. Pero en la muerte de Leovigildo el autor de las $V S P E$ ha introducido un segundo motivo en otro buen ejemplo de utilización y adaptación de sus fuentes, que antes he llamado hábil y ahora cabe calificar de sabia (tal vez erudita) ${ }^{60}$; es además intencionadamente política o, mejor dicho, malintencionadamente política, tendenciosa: es el retornelo machacón de Lactancio de que todos y cada uno de los emperadores perseguidores han sido también malos emperadores, es decir, malos gobernantes y malos moralmente ${ }^{61}$. Eso mismo era también Leovigildo: no beneficia-

que fue presa de una enfermedad muy grave (grauissimoque morbo... correptus $=$ Vita Desiderii 19, 6 ss., p. 66 Theudericus... desinterico morbo correptus).

Por otra parte, también el obispo arriano Sunna murió "cruelmente», como Leovigildo, castigado por Dios (XI 80-81 diuino protinus multatus iudicio crudeli exitu uitam finibit).

${ }^{58}$ Del Dios vengador, colérico y terrible, que el autor saca a relucir en VSPE II 63 ss., p. 18, cuando unos niños del monasterio emeritense de Cauliana (recuérdese el topos del puer senex) amonestan a un monje glotón, borracho y cleptómano, cargado de años: Considera iudicium terribilem Dei. Considera tremendi eius examinis metuenda sententia. [Hic] Considera formidandam atque orrendam eius iudicii ultricem seueritatem.

${ }^{59}$ IX 3-9 (Leouegildus) deserens usquequaque Deum, ymmo derelictus ipse a Deo, regnum simul cum uita infeliciter perdidit grauissimoque morbo Dei iudicio correptus uitam fedissimam amisit et mortem sibi perpetuam adquisiuit crudeliterque e corpore eius anima resoluta, perpetuis penis detemta, perenniter Ereui mancipata Tartaris non inmerito tenetur religata picibus semper bullientibus undis arsura $=$ Vita Desiderii 19 , 6-9, p. 66 Theudericus deserens Deum, immo derelictus ipse a Deo... desinterico morbo correptus uitam fedissimam perdidit et amicam sibi mortem perpetuam acquisiuit + $21,13-14$, p. 67 Taliter terrena materie anima (Brunigildis) resoluta perpetuisque penis nec immerito relegata tenetur piceis arsura bullientibus undis.

${ }^{60}$ Demasiado tarde (no me resisto a comentarlo), cuando ya era inevitable porque el libro estaba en la calle, descubri en las $V S P E$ una frase literal de Salustio, que ha llegado aquí no sé cómo, pero que viene a darme la razón en lo que comentaba en el aparato crítico, porque para mayor mosqueo mío aparece en un pasaje problemático: Sal., Catil. LIV 2 Caesar beneficiis ac munificentia magnus habebatur es idéntico (transcribo todo su contexto) a VSPE V, III 47 ss. (Masona) Donabat multa, largiebat plurima, ditabat munificentia uniuersos beneficiis et munificentia magnus habebatur; proponia en el aparato crítico dos alternativas: o suprimir el primer munificentia, que se ha repetido a partir del segundo, o poner una coma después de uniuersos. A la vista del texto de Salustio me inclino ahora por unificar las dos posibilidades suprimiendo el primer munificentia, con lo que quedan tres frases bimembres, y colocando una coma tras uniuersos con todo el párrafo en asíndeton.

"1 Aunque el concepto de emperador «malo» tiene en Lactancio otros matices más complejos que el simple enunciado a que yo lo he reducido (J. Moreau, Lactance. De la mort des persécuteurs, París 1954, p. 55 ss. [Sources Chrétiennes 39]; Ramón Teja en la introducción a Lactancio. Sobre la muerte de los perseguidores, Madrid 1982, p. 23 ss.). 
ba en nada a Hispania, la perjudicaba y, en vez de gobernarla, la conducía a la ruina (IX 1-2 Igitur quum non prodesset, sed obesset et magis perderet quam regeret Leouegildus Spaniam...); pero es que encima era un depravado que reunía todos los vicios (IX 2-3... nec quippiam de flagitiis uel facinoribus remaneret quod non proprium sibi defenderet), por lo que merece el castigo de Dios y la muerte (iudicio Dei, que no está en Sisebuto). Como digo, el texto es otra adaptación de la Vita Desiderii ${ }^{62}$, pero la diferencia es radical: en la Vita Desiderii el mal gobierno de los reyes francos y sus vicios, como en el caso de los profetas del Antiguo Testamento (more nempe prophetico, dice Sisebuto), son el objeto de la denuncia de Desiderio, que conduce al desenlace final del conflicto con los reyes y a la muerte del obispo; en el caso de las VSPE el mal gobierno y la degradación moral de Leovigildo, como en el caso de Lactancio, es un motivo asociado a su muerte. Y todavía el autor de las VSPE ha incorporado para mofa y mayor descrédito de Leovigildo algo más de su cosecha, una burla: la frase regnum simul cum uita infeliciter perdidit, absolutamente original y que no está en Sisebuto, es la carcajada, el grito de alegría, la parodia y la versión in malam partem ofrecida por el diácono de Mérida de la fórmula aclamatoria anno feliciter... regni ${ }^{63}$, que a partir de Recaredo, pero instaurada por Hermenegildo ${ }^{64}$, para el cómputo de los años del reinado de los monarcas recorre las inscripciones, pizarras, concilios, leyes y algún que otro texto histórico, como signo distintivo de los reyes visigodos católicos para diferenciarse de sus antecesores arrianos ${ }^{65}$.

Con todo la impresión final es mayor, si cabe, que en la Vita Desiderii, porque la historia puso aquí al servicio del autor un contrapunto muy efectista: el tono que trasluce la pintura de la muerte de Leovigildo es tan resentido, vengativo y hasta sarcástico como triunfalista el de la entronización de Recaredo (IX 10-26, pp. 79-80), príncipe ortodoxo y católico (IX 14 uir... per omnia catholicus) ${ }^{66}$, que "predica» (IX 20 sanc-

62 Vita Desiderii 15, 3-10, p. 62 Cum non prodesse, sed obesse et magis perdere quam regere Theudericus pariter et Brunigildis uitiis cernerentur infecti... neque quippiam de flagitiis uel facinus remaneret, his Dei martyr malis inspector et pontifex more nempe prophetico clangore tube personuit seseque totum pro depellendis erroribus eorum inuexit...

${ }^{63}$ Con el ordinal correspondiente intercalado entre feliciter y regni. El regnum... infeliciter de las VSPE se corresponde con el feliciter... regni del cliché.

o4 En la famosa inscripción de Alcalá de Guadaira: ... anno feliciter secundo regni domini nostri Erminigildi regis... (J. Vives, Inscripciones cristianas de la España romana y visigoda, Madrid-Barcelona 1941-1942, n. ${ }^{\circ} 364$, p. 127).

${ }_{65}$ Pero sobre todo esto y en particular sobre la fórmula anno feliciter volveré en otro momento, porque tal vez pueda explicar su origen.

${ }_{66}$ Cf. Pass. Sebastiani 9, 4, Fábrega, p. 150 Sabastianus, uir per omnia christianissimus. 
tam Trinitatem coeternam uniusque uirtutis et substantie predicans) ${ }^{68}$ la ortodoxia de la Trinidad, un Constantino redivivo, como viene a decir Juan de Bíclaro, personaje que, por cierto, también sufrió la persecución de Leovigildo y que también saluda "felizmente» la llegada de la era de Recaredo ${ }^{69}$.

\section{Las VSPE y las pasiones del Pasionario Hispánico}

Un último aspecto importante de la influencia de las pasiones en las $V S P E$, que no hace más que incidir de una manera, si cabe, todavía más evidente en la impronta dejada por aquéllas a lo largo de todo el texto y ya no sólo en el episodio de Leovigildo y Masona, es el de las imitaciones y los préstamos literales procedentes de las pasiones que han quedado en ellas.

A través de estos préstamos podemos conocer qué pasiones manejó el diácono de Mérida que redacta las VSPE y, de otra parte, puesto que conocemos la fecha aproximada de redacción de esta obra, establecer una cronología para el conocimiento y difusión de estas pasiones en la España visigoda, tal como ya hizo Díaz y Díaz usando como referencia la Vita Fructuosi y los escritos de Valerio del Bierzo ${ }^{70}$; a la vez (aunque la cuestión me parece mucho más compleja) podemos hacernos una idea del estado de nuestro Pasionario a mediados del siglo vII.

Puede asegurarse que conoció la Passio Iuliani et Basilissae, que ya Díaz y Díaz supone conocida en la península por los ecos de esta pasión en la Vita Fructuosi y en Valerio del Bierzo. Mas hay que adelantar algunos años esta presencia. Doy algunos casos de las abundantes huellas que quedan en la obra:

Pass. Iuliani

4, 15, p. 119 Florebat inclausa uisceribus eius perfecta caritas.
$V S P E$

V, II 22 in omnium corda florebat perfecta karitas.

${ }^{67}$ En VI 15-16 el autor habla de Leovigildo como Arrianorum regem.

${ }_{68}$ Misma expresión referida a Recaredo en Greg. M. Dial. III 31, 8 uerae fidei praedicator, pero sobre todo Isid. Hist. Goth. 53 praedicans trium personarum unitatem in Deum, filium a patre...

${ }^{69}$ Chronicon s. a. 587 (Mommsen, MGH, AA XI, p. 217; J. Campos, Juan de Biclaro. Su vida y su obra, Madrid 1960, p. 94) Anno V Mauricii principis Romanorum qui est Reccaredi regis primus feliciter annus.

${ }_{70}$ "Anotaciones para una cronología del Pasionario Hispánico" en Miscelánea en memoria de Dom Mario Férotin, Madrid-Barcelona 1966, pp. 515-528, y el artículo citado en nota 4 , p. 50 . 
21, 2, p. 127 Martianus preses, consilio diaboli armatus.

22,11, p. 128 reatu tuo oppressus.

33, 1-2, p. 132 Quumque eius aspectibus sisterentur.

$35,4-5$, p. 133 extimans pena terreri quos blandimentis superari non ualuit.

41,7, p. 135 Quid prodeest ceco, quando sol oritur?

42,4, p. 135 Ducebar a nescio quibus eziopibus, quorum status erat ut gigantum.

47, 2-3, p. 137 rapidissimo cursu... properat.
V, IV 9 (Leouigildus) consilio diabolico armatus.

V, XIII 57 reatu suo oppressus.

V, VI 66 Qui quum eius obtutibus sisteretur.

V, IV 27-28 opinans minis posse concutere quem blandimentis superare nequiuisset.

V, VI 128 Sed quid ceco prodesse poterat iubar splendidissimum solis?

IV, IX 21 apparuerunt... eziopes..., quorum statura uidebatur esse gigantea.

IV, IX 5-6 cursuque rapidissimo properans.

Lo mismo cabe decir de la Passio Eugeniae et comitum, de la que ya Garvin y Díaz y Díaz presentaron algún texto paralelo. Añado algunos más:

\section{Passio Eugeniae}

3, 1, p. 83 perfectissime docuisset.

7,4 , p. 85 cepit cum eo uerborum ingens habere luctamen.

13,4 , p. 87 ut unam eam dicerent ex numero angelorum.

18,9, p. 89 declinans ad maiorem interitum.

18,11, p. 89 Quumque ad eam uisitandam.

26, 11-12, p. 92 amplexibus eius incumbunt.

$32,3-4$, p. 94 mutuis secum fruebantur aspectibus.
VSPE

IV, IV 5-6 perfectissime docuit.

V, V 77-78 cepere utrique inter se uerborum ingens habere certamen.

IV, IV 11-12 ut unum illum putarent ex numerum angelorum.

II 19 ad maiorem declinans interitum.

I 7 Quumque ad eum uisitandum.

IV, III 22 amplexibus eius incubuit.

$\mathrm{V}, \mathrm{X} 31$ se mutuis alternisque cernerent aspectibus.

Muy interesante se revela el conocimiento que el autor manifiesta de la Passio Agnetis, que no se consideraba difundida en España hasta el siglo $\mathrm{IX}^{71}$. Los textos siguientes son las primeras menciones literarias de esta pasión y una prueba de su presencia y difusión en la España visigoda ya antes de mediados del siglo viI:

\section{Passio Agnetis}

4, 1, p. 177 Ad hec beata Agnes talem fertur iuueni dedisse responsum.

7, 3, p. 177 dehinc terroribus pulsat.

7,4 , p. 178 Sed Christi uirgo nec blandimento seducitur nec terrore concutitur, sed...
VSPE

V, VI 71 Ad hec uir Domini talem fertur dedisse responsum.

V, IV 27 cepit multis pulsare terroribus.

V, IV 28-29 Sed uir sanctus nec terroribus frangitur nec blandimentis suaditur, sed...

\footnotetext{
71 A. Fábrega, p. 179; Carmen García Rodríguez, citada en nota 4, p. 174.
} 
$8,2-3$, p. 178 quumque omnis sermo eius casso labore deficeret.

$26,1-2$, p. 181 quum nimia esset celi serenitas, tante coruscationes tantaque fulgura ac tonitrua extiterunt ut...
V, IV 26 Quumque se ille cerneret casso labore deficere.

V, VI 99 Dum... esset multa celi serenitas, maiestas diuina... intonuit ita ut...

Igualmente la procesión de santos, en la que participa el obispo Fidel (IV, VII, 17-26), además de algún préstamo literal evidente, está inspirada en la procesión de vírgenes mártires, entre las que también se ve a Inés, de Passio Agnetis 26, 9-13, p. 181 (texto que no transcribo por su extensión).

Hay al menos un texto para suponer que también conoció la Passio Agathae, que no se consideraba conocida en España hasta el s. Ix (Fábrega, p. 184) o el viII (Carmen García R., p. 181). El texto de V, VIII 77-78 Et sicut quispiam sitiens in ardore caumatis fluenta fontium concupiscit, sic ille... peruenire meruit, que Garvin (p. 479) consideraba dependiente de diversos pasajes bíblicos ${ }^{72}$, es una cita casi literal de Pass. Agathae 4, 13-14, p. 221 Et sicut sitiens in ardorem solis non nisi fluenta fontium concupiscit, ita illa... desiderabat... peruenire ${ }^{73}$.

Lo mismo cabe decir de la Passio Geruasii et Protasii, también considerada conocida muy tardiamente en España, finales del siglo Ix o principios del $x$ (Fábrega, p. 184). Es incuestionable que IV, I 1-2 sanctum uirum nomine Paulum, natione Grecum, arte medicum es un calco de Pass. Geru. et Prot. 6, 3-4, p. 280 christianum quendam nomine Vrsicinum, arte medicum, natione Ligurium.

Menos seguridad me inspiran las correspondencias con otras pasiones, aunque en más de algún caso sean exactas, que someto a la consideración del lector. Citaré dos pasajes de la Passio Adriani: el primero es 10, 9, p. 269 libentissime enim cum eis moriar, que tiene su equivalencia en V, XI 68-69 pro religione... libentissime moriar; el segundo es 27 , 3 , p. 275 delicatis cibis, del que tal vez pudiera depender V, III 19-20 ciuos delicatos. Mencionaré también otro de la Passio Andreae: en 9, 2122 , p. 63 Sed quia... me putas minas tuas posse formidare, quicquid tibi uidetur in suppliciis magis excogita (más Passio Romani 4, 5, p. 19 quid aduersum me cogitans... imperasti?) parece inspirado V, VI 86-87 minas

${ }^{72}$ Eccli. 26, 15 sicut uiator sitiens ad fontem os aperiet; Is. 35, 17 sitiens in fontes aquarum; Psalm. 41, 1 Quemadmodum desiderat ceruus ad fontes aquarum, ita desiderat anima mea ad te, Domine.

${ }^{73}$ La variante de VSPE, ardore caumatis, se lee en la Vita Antonii 54, 2, 8 et ardor erat caumatis ingentissimus (ed. G. J. M. Bartelink, Fondazione Lorenzo Valla, 1974 , p. 108), en una versión latina anónima de la obra de Atanasio, distinta de la de Evagrio (cauma es un término griego). 
tuas non formidabo. Sed quidquid ualet mens tua peruersa amplius aduersum me excogitet.

No encuentro dependencias claras, que no sean lugares comunes, de las pasiones de mártires hispanos, si se exceptúa la muy antigua de san Vicente: quizá VI 47-48 cepit rauido ore rauidioribus aduersus Dei famulum infrendere latratibus y VI 65-66 acrius infrendere cum dentium stridore contra uirum Dei diabolus cepit puedan estar inspirados por 10, 1-2, Fábrega, p. 189 diabolus fremere cepit, rabidioribus intonare sermonibus, stridore dentium frendere.

Dentro de este contexto de la cronología de la difusión de las pasiones en la España visigoda y relacionado con las VSPE, no está de más volver a recordar que hay una pista segura para fechar la presencia de la Passio Genesii a mediados del siglo viI: es el epílogo de la más antigua versión de la Vita Fructuosi que se nos ha conservado interpolada en las VSPE y que probablemente sea originaria de Mérida, donde no es un azar que por estas fechas tenga lugar una deposición de reliquias del mártir Ginés ${ }^{74}$. El texto del epílogo 3-7 ne ea que adhuc uiua recordatione, ut sunt gesta, referuntur, euanescente tempore uel tradentium uel accipientium fide, fabulosa credantur procede de Pass. Genesii 2, 10-13, p. 334 ne ea que adhuc uiua recordatione rerum, ut sunt gesta, referuntur, euanescente per tempus uel tradentium uel accipientium fide, fabulosa credantur ${ }^{75}$.

Antonio Maya S.

${ }^{74}$ Véase la introducción de mi edición de las VSPE, p. XXXIX, nota 92, y Habis 9, p. 183, nota 16. El texto del epílogo en pp. LXXXVIII-XC (= Habis 9, pp. 179-181).

${ }^{75}$ Quedan dos cuestiones de difícil solución, sujetas a la cronología, imprecisa y discutida, de las obras de referencia: una es la dependencia de la Passio Mantii 9 infinite edis longe lateque spatia... tecta texuntur de VSPE IV, VI 25-29 edificii spatia longe lateque... tecta contexuit o a la inversa, según la cronología que se acepte (véase M. C. Díaz y Díaz, Analecta Bollandiana 100, 1982, p. 327 ss.; J. M. ${ }^{a}$ Fernández Catón, San Mancio. Culto, leyenda y reliquias, León 1983; y Juan Gil, "Interpretaciones latinas", Habis 15, 1984, pp. 189-193); la otra afecta a la correspondencia entre VSPE V, XIV 2-3 uir... nomine Innocentius, cuius meritum nominis indicabit uocabulum y Pass. Leocadiae 5, 4-5, Fábrega, p. 67 (= Pass. Vincentii, Sab. et Crist. 4, 5 , p. 359) adulescentem quendam nomine Vincentium, cuius meritum nomini comitabatur suo (cf. Díaz y Díaz, citado en nota 70, p. 525, nota 26). 